\title{
Patient-derived xenograft mouse models: A high fidelity tool for individualized medicine (Review)
}

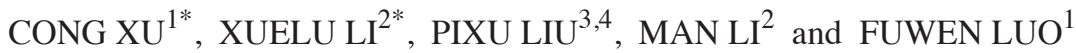 \\ Departments of ${ }^{1}$ Acute Abdomen Surgery, ${ }^{2}$ Breast Surgery and Oncology, The Second Hospital of \\ Dalian Medical University, Dalian, Liaoning 116023; ${ }^{3}$ Institute of Cancer Stem Cell; \\ ${ }^{4}$ College of Pharmacy, Dalian Medical University, Dalian, Liaoning 116044, P.R. China
}

Received July 5, 2016; Accepted May 16, 2017

DOI: $10.3892 / \mathrm{ol} .2018 .9583$

\begin{abstract}
Patient-derived xenograft (PDX) mouse models involve the direct transfer of fresh human tumor samples into immunodeficient mice following surgical resection or other medical operations. Gene expression in tumors may be maintained by serial passages of tumors from mouse to mouse. These models aid research into tumor biology and pharmacology without manual manipulation of cell cultures in vitro. and are widely used in individualized cancer therapy/translational medicine, drug development and coclinical trials. PDX models exhibit higher predictive values for clinical outcomes than cell line-derived xenograft models and genetically engineered mouse models. However, PDX models are associated with certain challenges in clinical application. The present study reviewed current collections of PDX models and assessed the challenges and future directions of this field.
\end{abstract}

\section{Contents}

1. Introduction

2. Introduction of animal models

3. Broad utility of PDXs

4. Disadvantages of PDX

5. Perspective

Correspondence to: Dr Fuwen Luo, Department of Acute Abdomen Surgery, The Second Hospital of Dalian Medical University, 467 Zhongshan Road, Dalian, Liaoning 116023, P.R. China

E-mail: fuwenluo@yeah.net

Dr Man Li, Department of Breast Surgery and Oncology, The Second Hospital of Dalian Medical University, 467 Zhongshan Road, Dalian, Liaoning 116023, P.R. China

E-mail:dmulixl@163.com

${ }^{*}$ Contributed equally

Key words: patient-derived xenograft mouse models, individualized cancer therapy, genetically engineered mouse models, cell line-derived xenografts

\section{Introduction}

Anticancer drugs may be tested in vitro or in vivo using multiple preclinical models. Though $>2 / 3$ of agents are tested safely in phase I of clinical trials, the predictive accuracy of drug effectiveness is unsatisfactory in phase II due to the loss of heterogeneity and the specific cell microenvironment and alterations to the mechanism of tumorigenesis (1-3). Therefore, a model to guide individualized medicine is required.

In traditional cell lines, established cells are cultured in artificial conditions that may not accurately simulate complex biological conditions, including tumor progression in low oxygen conditions (4), excessive hypoxia-induced transcription factor activation (5), immune escape mechanism deficiency (6) and angiogenesis (7). In addition, autocrine, paracrine and endocrine mechanisms also serve key functions in tumor development, particularly in breast, ovarian and prostate cancer (8-10). Therefore, in vitro-based culture experiments may be inappropriate for individualized medicine.

Patient-derived xenograft (PDX) mouse models were initially proposed 40 years ago. With the development of host animals, numerous academic organizations have renewed their interest in PDX models. PDXs involve the direct transfer of fresh tumor samples into immunodeficient mice following surgical resection or other medical operations. Gene expression in tumors may be maintained by serial passages of tumors from mouse to mouse (11). PDXs aid research into tumor biology and pharmacology without manual manipulation of cell cultures in vitro. Multiple PDX studies have reported that, compared with their corresponding parental tumors, PDXs retain sufficient fidelity regarding histology, the transcriptome and genome (12-16). The present study reviewed current collections of PDXs and evaluated the key issues facing their future application.

\section{Introduction of animal models}

Current animal models. Numerous academic institutions have begun renewing their interest in genetically engineered mouse models (GEMMs), cell line-derived xenografts, and PDX models.

GEMMs. GEMMs are classified into two categories: Transgenic and targeted. In transgenic GEMMs, exogenous oncogenes are 
expressed through pronuclear injection of embryonic stem cells. Targeted GEMMs involve homologous recombination in mouse embryonic stem cells, in which targeting vectors modify the homologous arms of a genomic locus to the accuracy of a single base. GEMMs have been used to elucidate multiple aspects of cancer development. Khaled et al (17) summarized data from multiple studies. For example, GEMMs are particularly suitable for deleting or overexpressing targeted genes in a tissue-specific manner, are easy to produce and use endogenous regulatory elements. However, establishing the model takes $\sim 1$ year. Another major disadvantage of GEMMs is the low success rate between two targeted sites. In addition, GEMMs may not be able to mimic the individualized therapy associated with a tumor-specific gene. Therefore, GEMMs may not represent the optimal preclinical trial model.

Cell line-derived xenograft models. Cell lines are transplanted into immunodeficient mice to establish tumor models by numerous means, including subcutaneous implantation and orthotopic, venial or peritoneal injection. In 2007, Hajitou et al (18) established the first soft tissue sarcoma cell line-derived tumor in the hind limb of rats. Subsequently, the development of cell line-derived xenograft models has decreased the influence of irrelevant cells when studying a single factor (16), improved the use of experimental cellular operations in researching tumor-associated signaling pathways and molecular mechanisms $(19,20)$, established acute myeloid leukemia animal models to mimic the progression of liquid tumors (21), and aided research into metastatic mechanisms via intravenous or intraperitoneal injection (22). In addition, cell line-derived xenograft mouse models are easily established, and generating tumors takes only 2-8 weeks (23).

However, since generating cancer cell lines may irreversibly alter the biological properties of the derived cells, cell line-derived xenografts have limited predictive value for cancer therapy. The major disadvantages of this model are as follows: Following the dissociation of tumor tissues into a single cell suspension in vitro, selection pressure tends to result in a decrease in the heterogeneous characteristics of the tumors; not all cell lines are suitable for patients with certain types of cancer (17) and cell lines may not accurately reflect the complexity of tumor heterogeneity (24), which impacts patient-specific responses to clinical therapy. Therefore, cell line-derived xenograft models may not satisfy the requirements of individualized medicine.

PDX models. Compared with GEMMs and cell line-derived xenograft models, PDX models have more predictive value for clinical outcomes $(25,26)$. Multiple studies have reported the high fidelity of PDXs regarding histology, the transcriptome and genome (12-16). Previous studies have obtained more detailed data on tumor cell population dynamics using deep-genome and single-cell sequencing techniques in PDXs for breast cancer $(27,28)$. Therefore, the present study suggests that PDXs may be optimal models for studying tumor heterogeneity and currently represent the most powerful tool for assessing cancer-associated mechanisms. However, PDXs remain to be popularized in clinical application. Thus, the present study reviewed the progression of PDXs, particularly the challenges faced by these models, and future directions for individualized medicine (Table I).

Existing PDX mouse models. PDXs may have originally failed to enter mainstream cancer research due to the limitations of using host animals that are not sufficiently immunodeficient and initiate xenograft rejection. However, using animal models is now common, since the number of immunodeficient host animal models has increased and the cost of immunodeficient mice has decreased (29). At present, nude, nonobese diabetic (NOD)/severe combined immunodeficiency (SCID) and NOD SCID $\gamma$ (NSG) mice represent the three most commonly used types of immunodeficient mice. Nude mice are athymic, which results in a congenital deficiency of $\mathrm{T}$ and normal $\mathrm{B}$ lymphocytes and enhanced activity of natural killer (NK) cells (30). NOD/SCID mice are generated by crossing C.B.-17-SCID mice with NOD mice. SCID and NOD/SCID mice exhibit a congenital deficiency of $\mathrm{T}$ and B lymphocytes; the latter also exhibits decreased NK cell activity, which aids the use of the model since residual NK cells serve a key function in rejecting human tissues. NSG mice exhibit a deficiency of the interleukin 2 receptor $\gamma$-chain via the genetic engineering of NOD/SCID mice. NSG mice are the most severely immunodeficient since they exhibit $\mathrm{T}$, $B$ and NK cell deficiency. Therefore, the engrafting success rate in NSG mice is typically increased compared with that in nude or NOD/SCID mice (31). Therefore, NSG mice may be the most suitable of the three to generate tumors (32). NSG mice have been successfully utilized in multiple types of cancer and the present study has summarized the current state of PDXs (Table I).

Additional PDX models. Circulating tumor cells (CTCs) are released from primary tumors into peripheral blood vessels. Conditions permitting, CTCs may infiltrate distant tissues and thereby induce metastasis by providing 'seeds' to distant organs, in accordance with the 'seed and soil' theory (33). CTCs represent a readily accessible method for liquid biopsy. Numerous researchers over the past decades have focused on identifying and improving technically challenging methods of isolating CTCs (34). Currently, the CellSearch System is the only Food and Drug Administration-approved technique for CTC enumeration (35). However, the CellSearch System depends on epithelial cell adhesion molecules (EpCAMs) and therefore may only identify a small number of CTCs, potentially resulting in false negative or positive readings (36). Therefore, researchers have previously used the brain metastasis-selected markers (BMSMs) erb-b2 receptor tyrosine kinase 2 (ERBB2) + epidermal growth factor receptor $(\text { EGFR })^{+} /$heparanase ${ }^{+} /$notch $^{+}{ }^{+}$to identify EpCAM- CTCs (37). The infiltration and metastasis of these CTCs were analyzed using BMSMs and these cells were then demonstrated to be invasive and capable of generating brain or lung metastasis in nude mice. Researching EpCAM- CTCs may also serve to improve the understanding of metastasis. Enrichment steps are crucial to increase the isolation success rate. Although enriching CTCs may reach $98 \%$ of total CTCs by using the CTC-Chip, this chip has not become available on the market yet (38). Previously, the drug sensitivity of cultured CTCs was tested among multiple CTC lines (39). Furthermore, 


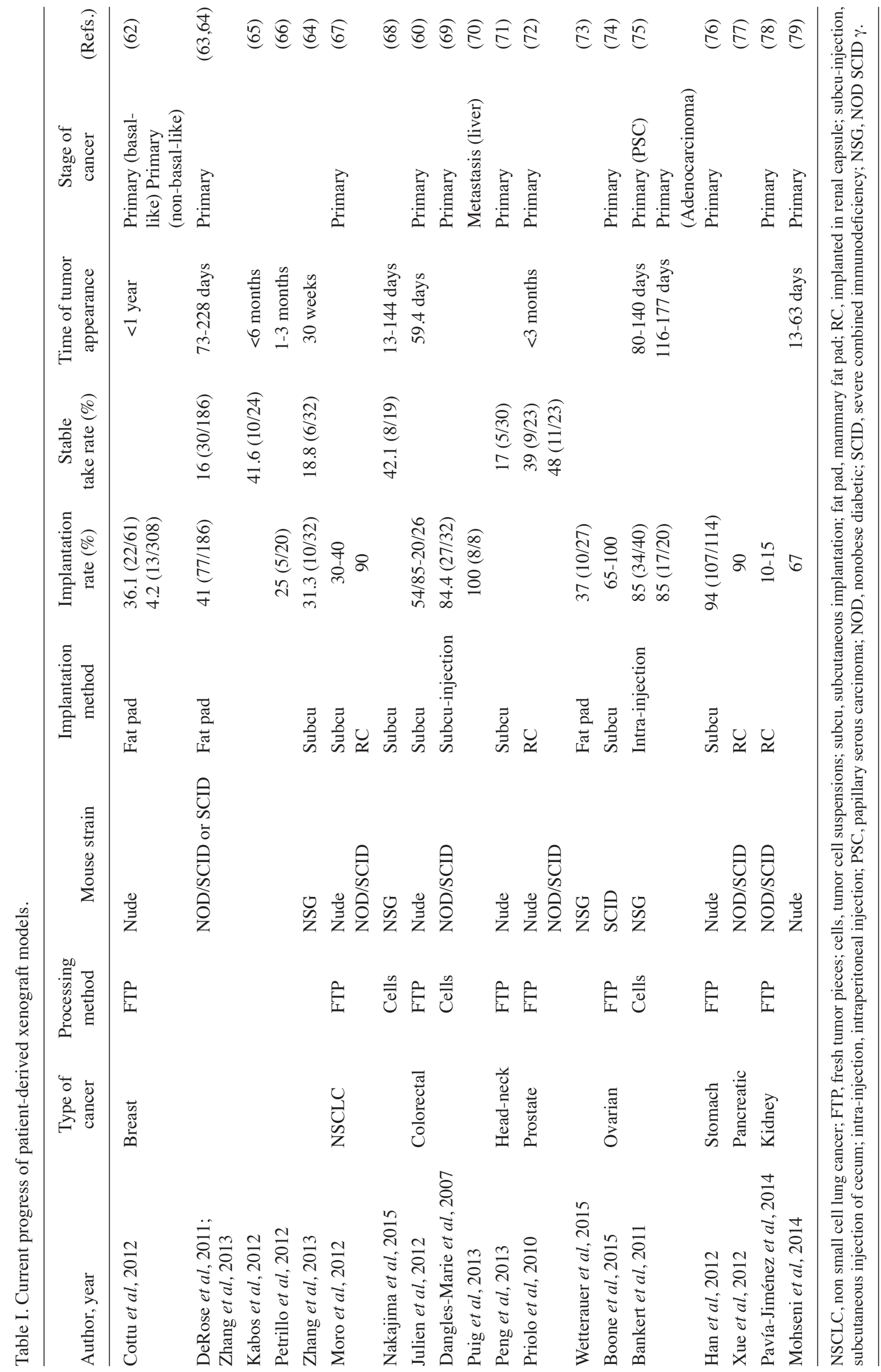


another study demonstrated that testing the drug sensitivity of CTC lines for clinical regimes is in accordance with the clinical treatment response (40). Drug sensitivity testing of CTCs may predict the donor patient's response and direct appropriate therapy for individualized medicine. In addition, CTC-derived xenografts have been used in the laboratory for studying certain types of cancer. One institution reported that the PDXs for small cell lung cancer (SCLC) may reflect the responses of patients to clinical regimes (34). Therefore, CTC-derived xenograft models (CDXs) may be used to detect drug resistance mechanisms.

\section{Broad utility of PDXs}

Individualized cancer therapy/translational medicine. PDXs are maintained by passaging tumor tissues directly from mouse to mouse. Heterotopic or orthotopic PDXs involve implanting tissues into the subcutaneous flank or the organs of mice. PDXs are considered to be superior to traditional cell line xenografts since the former may be more similar to parental tumors compared with the latter, particularly in terms of tumor, intratumor and intrametastasis heterogeneity (26). Traditional tumor models exhibit poor predictive values due to the associated heterogeneity. The development of PDXs satisfies the requirements of an effective preclinical tool, and PDXs are a predictive model of carcinogenesis physiology and clinical therapy. As genomic research develops, further subtypes of cancer are predicted. For example, five molecular subtypes of breast cancer have been characterized, studied and categorized using the Prosigna Breast Cancer Prognostic Gene Signature assay test: Luminal A, luminal B, ERBB2+, basal-like and normal-like (41). Subtypes are further divided into more detailed types for each individual in clinical practice $(42,43)$.

In addition, studies on targeted drug treatments confirm the accurate predictive value, fidelity and stability of PDXs and PDX-associated clinical prognosis (Fig. 1A, B and C).

In 2014, Stebbing et al (44) established PDXs using puncture tissues derived from 29 patients with advanced sarcoma, and tissues derived from 16 of the 29 patients successfully established PDXs. According to the results of the study, 6 of the patients benefited from PDX-guided therapy. The remaining patients exhibited an association between clinical outcomes and their PDXs as demonstrated by retrospective analysis. In 2014, Elena Garralda et al (45) combined next-generation sequencing with PDXs to guide individualized treatments for 25 patients with advanced solid tumors. The most effective individualized drugs were selected according to the sequencing results of the PDXs. Subsequently, 14 of the 25 patients received personalized treatments, and 11 achieved durable partial remission. Subsequently, PDX models have increased in popularity.

The use of PDXs is advantageous in drug-screening and resistance mechanism research. PDXs possess an effective predictive value in targeted drug-screening for clinical treatments. The development of optimal regimes, based on drug-screening in PDXs, may improve the survival rate of patients with cancer. Furthermore, gene mutations cause tumorigenesis, particularly those in p53 and phosphatase and tensin homolog $(24,46)$. Although gene mutations may be identified using whole-genome sequencing, identifying the significant mutations with which specific diseases are associated remains a challenge. Therefore, Berg et al (47) aimed to construct a comprehensive dataset, including driver mutations, tumorigenicity variants and clinical responses, but this was discovered to be time-consuming. In addition, drug resistance mechanisms may consist of primary or acquired resistance (48). PDXs may represent intratumor and intrametastasis heterogeneity, and more accurately predict resistance mechanisms to clinical treatments. Therefore, PDXs may potentially represent a platform for evaluating personalized resistance mechanisms. Personalized medicinal strategy may become a future direction for personalized treatment and translational medicine.

Drug development. The poor predictive value of the preclinical models used to select novel drugs is partly responsible for the low success rate of novel agents in clinical application. PDXs are more predictive of clinical outcomes and possess a vast development foreground in the preclinical screening of novel anticancer drugs. Chiron et al (49) compared the anticancer effect of aflibercept with that of bevacizumab by using PDXs in multiple genetic backgrounds, demonstrating that aflibercept had increased anticancer functions compared with bevacizumab. Monsma et al (50) revealed that vemurafenib was effective in PDXs of melanoma with B-Raf proto-oncogene, serine/threonine kinase (BRAF) ${ }^{\mathrm{V} 600 \mathrm{E}}$ or $\mathrm{BRAF}^{\mathrm{V} 600 \mathrm{~V}}$. Furthermore, the combination of mitogen-activated protein kinase inhibitors and vemurafenib improved the effectiveness of anticancer therapies. Consequently, screening of the susceptibility of drugs may be effectively integrated into clinical translational medicine (Fig. 1C and D).

Coclinical trials. Coclinical trials are characterized by parallel studies between mouse models and patients, which may help determine treatment strategies for patients and to identify underlying cancer-associated mechanisms with the aid of PDXs $(51,52)$. As cancer progresses, the drug becomes less effective and novel resistance mechanisms appear. When and how such mechanisms develop is unpredictable during clinical treatment. Drug resistance may be observed earlier with the aid of PDXs, which may assist in determining subsequent treatment regimes. GEMMs have been used in coclinical trials and exhibited positive results in parallel clinical trails (53), including those involving leukemia, melanoma, prostate cancer and non (N)SCLC (53-56). Furthermore, coclinical trials may also verify relevant hypotheses in a clinical setting and thereby affect the design of future clinical studies (57). However, this may be associated with increased costs (51). PDXs have not been used in large scale coclinical trials (38). Bertotti et al (38) reported that 8 patients with metastatic colorectal cancer were successfully treated using targeted PDX-based therapies combining anti-ERBB2 with anti-EGFR to predict resistance to anti-EGFR targeted therapy. Coclinical trials monitor the responses of individuals and parallel mouse models simultaneously and provide an in vivo model to research suspicious resistance mechanisms and test combination strategies for overcoming novel spontaneous resistance mechanisms (Fig. 1E). 


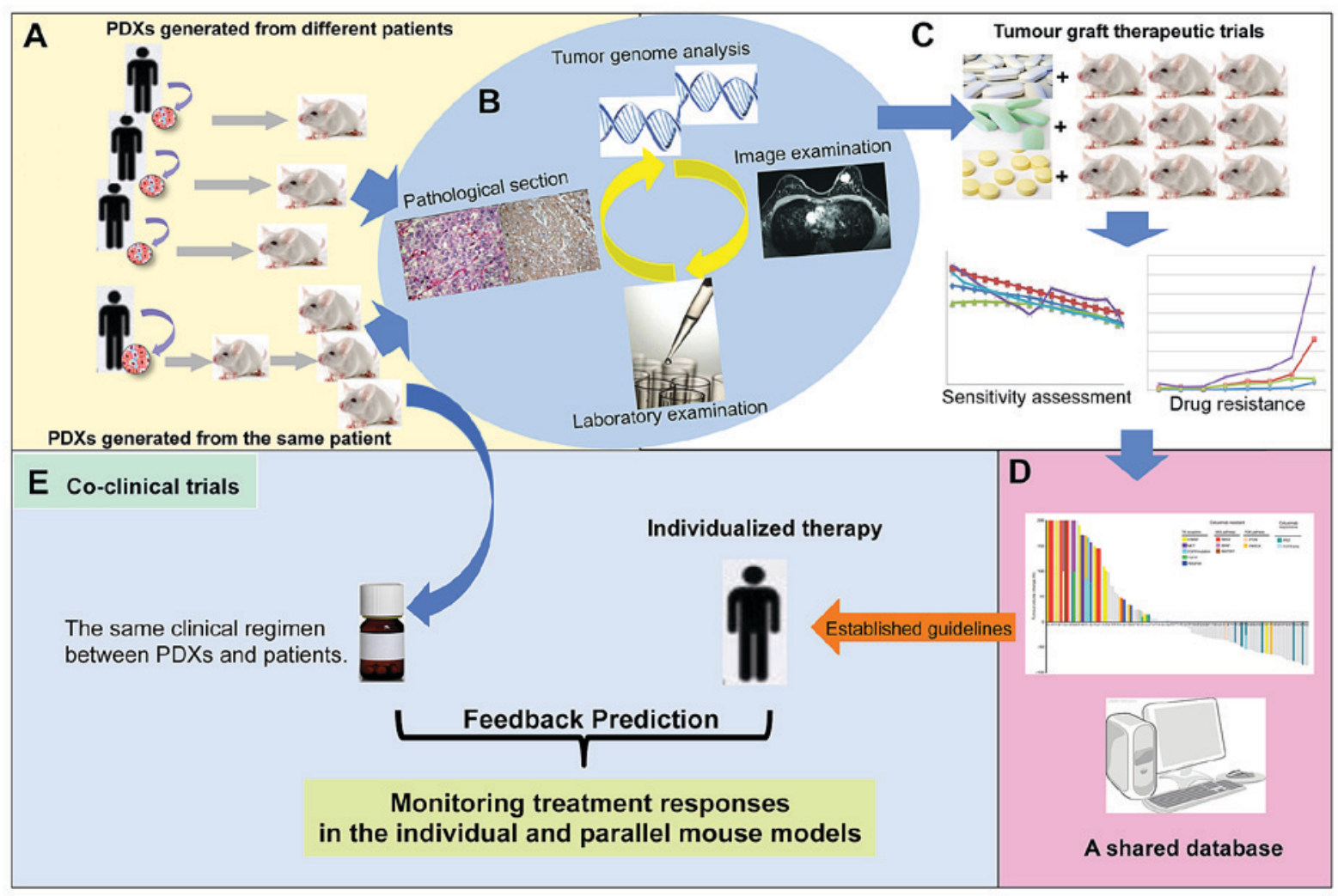

Figure 1. Concept of individualized therapy, drug development and coclinical trials. (A) Tumor graft expansion: PDXs generated from multiple patients or a single patient. (B) Overall preclinical analysis. (C) Preclinical testing of anticancer agents. (D) Establishment of a database to integrate genomic and therapeutic analyses. (E) In coclinical trials, an in vivo model to research suspicious resistance mechanisms in cancer cells may be developed. PDX, patient-derived xenograft.

\section{Disadvantages of PDX}

Though the application of PDXs in tumor research is associated with the aforementioned advantages, certain problems with PDXs remain. PDXs depend on murine immunodeficiency models, which lack functional elements of immune systems. Therefore, due to the lack of stromal cells and degradation of tissue architecture, the tumor microenvironment was virtually non-existent (58). In addition, murine fibroblasts differ from those in humans (45). Morton et al (59) successfully isolated CD34+ cells from the blood of patients and subsequently intravenously injected them into a mouse to reconstruct a functional immune system in murine models that would mimic that of patients. PDXs with patient-matched immune systems may be valuable for study, particularly when screening immune system-mediating agents.

Furthermore, less aggressive tumors exhibit decreased implantation rates and more aggressive tumors exhibit increased formation rates. For example, estrogen receptor-negative types of breast cancer exhibit increased the rate of successful tumor establishment compared with hormone-positive types of breast cancer (60). Patients with initial tumors may experience improved treatment outcomes compared with those with more advanced tumors. However, constructing a PDX model with initial tumor remains a challenge and tumor formation rate remains low. Therefore, improvement of the implantation rate is urgently required.

Developing PDXs delays treatment schedule and increases costs. Typically, at least 3 months are required to develop
PDXs that may be used for preclinical study. This is a major limiting factor for individualized medicine. Discovering the most suitable conditions for certain subtypes of cancer may decrease the duration of PDX generation. Another critical factor is cost, comprising cloned animal and whole-genome analysis cost and experimental preclinical expenses. Not all patients may be able to afford these costs. Therefore, PDXs remain technically challenging, time-consuming and costly.

\section{Perspective}

The Human Genome Project was launched in 1990 and has improved the understanding of the genome. However, gene function remains to be fully understood, including regulatory mechanisms and gene interactions. Under the complex background of individual differences, achieving accurate clinical use of the results of genomic analysis is challenging. Therefore, predictive models are crucial. PDXs may provide evidence to personalize clinical treatments for patients.

As aforementioned, the process of generating PDXs differs among researchers. Low engrafting rates are a major factor that restricts the personalized medicine development of PDXs. The aim of the next phase of PDX development is to identify the most appropriate conditions and methods to maximize tumor formation rates. There is an increasing trend in industry and academia to help develop PDXs. Hidalgo et al (61) have proposed the concept of the 'EurOPDX Consortium', which aims to establish a network of clinically relevant models of human tumors, 
particularly PDXs, and share the characteristics of currently available models. Successfully establishing this shared database globally may help to acquire analogical PDXs quickly by comparing data pertaining to certain patients, thereby altering traditional concepts of clinical treatment. Individualized therapy may be converted into programmatic therapy. By comparing clinical samples with samples in the database, the optimal treatment plan may be identified from the shared database in cases where genomic characteristics are similar or consistent between patients. Thus, treatment schedule delays and high costs may cease to be limiting factors in the clinical application of PDXs. The present study suggests that PDXs may be commonly used in treating patients with cancer in the future.

\section{Acknowledgements}

The authors would like to thank Professor Hailing Cheng and Chen Song (Department of Oncology and Cancer Institute, The Second Hospital of Dalian Medical University, Dalian China) for their guidance.

\section{Funding}

The present study was supported by grants from the Provincial Natural Science Foundation of Liaoning (grant no. 2015020316) and National Natural Science Foundation of China (grant no.81650018).

\section{Availability of data and materials}

Not applicable.

\section{Authors' contributions}

PL, ML and FL designed the review and revised the manuscript. XL and CX were responsible for manuscript drafting. All authors have reviewed the final version of the manuscript and approved it for publication.

\section{Ethics approval and consent to participate}

Not applicable.

\section{Patient consent for publication}

Not applicable.

\section{Competing interests}

The authors declare that they have no competing interests.

\section{References}

1. DiMasi JA, Reichert JM, Feldman L and Malins A: Clinical approval success rates for investigational cancer drugs. Clin Pharmacol Ther 94: 329-335, 2013.

2. Kola I and Landis J: Can the pharmaceutical industry reduce attrition rates?. Nat Rev Drug Discov 3: 711-715, 2004.

3. Rosfjord E, Lucas J, Li G and Gerber HP: Advances in patient-derived tumor xenografts: From target identification to predicting clinical response rates in oncology. Biochem Pharmacol 91: 135-143, 2014.
4. Chawla SP, Cranmer LD, Van Tine BA, Reed DR, Okuno SH, Butrynski JE, Adkins DR, Hendifar AE, Kroll S and Ganjoo KN: Van tine Phase II study of the safety and antitumor activity of the hypoxia-activated prodrug TH-302 in combination with doxorubicin in patients with advanced soft tissue sarcoma. J Clin Oncol 32: 3299-3306, 2014.

5. Schödel J, Grampp S, Maher ER, Moch H, Ratcliffe PJ, Russo P and Mole DR: Hypoxia-inducible transcription factors, and renal cancer. Eur Urol 69: 646-657, 2016.

6. Spranger S, Bao R and Gajewski TF: Melanoma-intrinsic $\beta$-catenin signalling prevents anti-tumour immunity. Nature 523: 231-235, 2015.

7. Rivera LB and Bergers G: Cancer. Tumor angiogenesis from foe to friend. Science 349: 694-695, 2015.

8. Mungenast $\mathrm{F}$ and Thalhammer T: Estrogen biosynthesis and action in ovarian cancer. Front Endocrinol (Lausanne) 5: 192, 2014.

9. Nwabo Kamdje AH, Seke Etet PF, Vecchio L, Muller JM, Krampera $M$ and Lukong KE: Signaling pathways in breast cancer: Therapeutic targeting of the microenvironment. Cell Signal 26: 2843-2856, 2014.

10. Attard G,Parker C, Eeles RA, Schröder F, Tomlins SA, Tannock I, Drake CG and de Bono JS: Prostate cancer. Lancet 387: 70-82, 2016.

11. Huang M, Shen A, Ding J and Geng M: Molecularly targeted cancer therapy: Some lessons from the past decade. Trends Pharmacol Sci 35: 41-50, 2014.

12. Sharpless NE and Depinho RA: The mighty mouse: Genetically engineered mouse models in cancer drug development. Nat Rev Drug Discov 5: 741-754, 2006.

13. Zhang R, Jin S, Rao W, Song F, Yin Q, Wang Y, Wang L, Xi Y, Zhang $\mathrm{X}$, Wang $\mathrm{M}$ and Ge H: OVA12, a novel tumor antigen, promotes cancer cell growth and inhibits 5-fluorouracil-induced apoptosis. Cancer Lett 357: 141-151, 2015.

14. Park H, Kim Y, Sul JW, Jeong IG, Yi HJ, Ahn JB, Kang JS, Yun J, Hwang JJ and Kim CS: Synergistic anticancer efficacy of MEK inhibition and dual PI3K/mTOR inhibition in castration-resistant prostatecancer. Prostate 75: 1747-1759, 2015.

15. Girotti MR, Lopes F, Preece N, Niculescu-Duvaz D, Zambon A, Davies L, Whittaker S, Saturno G, Viros A, Pedersen M, et al: Paradox-breaking RAF inhibitors that also target SRC are effective in drug-resistant BRAF mutant melanoma. Cancer Cell 27: 85-96, 2015.

16. Wykosky J, Hu J, Gomez GG, Taylor T, Villa GR, Pizzo D, VandenBerg SR, Thorne AH, Chen CC, Mischel PS, et al: A urokinase receptor-Bim signaling axis emerges during EGFR inhibitor resistance in mutant EGFR glioblastoma. Cancer Res 75: 394-404, 2015.

17. Khaled WT and Liu P: Cancer mouse models: Past, present and future. Semin Cell Dev Biol 27: 54-60, 2014.

18. Hajitou A, Lev DC, Hannay JA, Korchin B, Staquicini FI, Soghomonyan S, Alauddin MM, Benjamin RS, Pollock RE, Gelovani JG, et al: A preclinical model for predicting drug response in soft-tissue sarcoma with targeted AAVP molecular imaging. Proc Natl Acad Sci USA 105: 4471-4476, 2008.

19. Hu B, Nandhu MS, Sim H, Agudelo-Garcia PA, Saldivar JC, Dolan CE, Mora ME, Nuovo GJ, Cole SE and Viapiano MS: Fibulin-3 promotes glioma growth and resistance through a novel paracrine regulation of Notch signaling. Cancer Res 72: 3873-3885, 2012.

20. Kung PP, Martinez R, Zhu Z, Zager M, Blasina A, Rymer I, Hallin J, $\mathrm{Xu} \mathrm{M}$, Carroll C, Chionis J, et al: Chemogenetic evaluation of the mitotic kinesin CENP-E reveals a critical role in triple-negative breast cancer. Mol Cancer Ther 13: 2104-2115, 2014.

21. Saland E, Boutzen H, Castellano R, Pouyet L, Griessinger E, Larrue C, de Toni F, Scotland S, David M, Danet-Desnoyers $\mathrm{G}$, et al: A robust and rapid xenograft model to assess efficacy of chemotherapeutic agents for human acute myeloid leukemia. Blood Cancer J 5: e297, 2015.

22. Santel A, Aleku M, Röder N, Möpert K, Durieux B, Janke O, Keil O, Endruschat J, Dames S, Lange C, et al: Atu027 prevents pulmonary metastasis in experimental and spontaneous mouse metastasis models. Clin Cancer Res 16: 5469-5480, 2010.

23. Lee SH, Hong JH, Park HK, Park JS, Kim BK, Lee JY, Jeong JY, Yoon GS, Inoue M, Choi GS and Lee IK: Colorectal cancer-derived tumor spheroids retain the characteristics of original tumors. Cancer Lett 367: 34-42, 2015.

24. Vogelstein B, Papadopoulos N, Velculescu VE, Zhou S, Diaz LA Jr and Kinzler KW: Cancer genome landscapes. Science 339: 1546-1558, 2013. 
25. Zhang $X$ and Lewis MT: Establishment of patient-derived xenograft (PDX) models of human breast cancer. Curr Protoc Mouse Biol 3: 21-29, 2013.

26. Chou J, Fitzgibbon MP, Mortales CL, Towlerton AM, Upton MP, Yeung RS, McIntosh MW and Warren EH: Phenotypic and transcriptional fidelity of patient-derived colon cancer xenografts in immune-deficient mice. PLoS One 8: e79874, 2013.

27. Cho YB, Hong HK, Choi YL, Oh E, Joo KM, Jin J, Nam DH, Ko YH and Lee WY: Colorectal cancer patient-derived xenografted tumors maintain characteristic features of the original tumors. J Surg Res 187: 502-509, 2014.

28. Eirew P, Steif A, Khattra J, Ha G, Yap D, Farahani H, Gelmon K, Chia S, Mar C, Wan A, et al: Dynamics of genomic clones in breast cancer patient xenografts at single-cell resolution. Nature 518: 422-426, 2015.

29. Emes RD, Goodstadt L, Winter EE and Ponting CP: Comparison of the genomes ofhuman and mouse lays the foundation of genome zoology. Hum Mol Genet 12: 701-709, 2003.

30. Pelleitier M and Montplaisir S: The nude mouse: A model of deficient T-cell function. Methods Achiev Exp Pathol 7: 149-166, 1975.

31. Lapidot T, Fajerman Y and Kollet O: Immune-deficient SCID and NOD/SCID mice models as functional assays for studying normal and malignant human hematopoiesis. J Mol Med 75: 664-673, 1997.

32. Shultz LD, Lyons BL, Burzenski LM, Gott B, Chen X, Chaleff S, Kotb M, Gillies SD, King M, Mangada J, et al: Human lymphoid and myeloid cell development in NOD/LtSz-scid IL2R gamma null mice engrafted with mobilized human hemopoietic stem cells. J Immunol 174: 6477-6489, 2005.

33. Gupta GP and Massagué J: Cancer metastasis: Building a framework. Cell 127: 679-695, 2006.

34. Alunni-Fabbroni M and Sandri MT: Circulating tumour cells in clinical practice: Methods of detection and possible characterization. Methods 50: 289-297, 2010

35. Allard WJ, Matera J, Miller MC, Repollet M, Connelly MC, Rao C, Tibbe AG, Uhr JW and Terstappen LW: Tumor cells circulate in the peripheral blood of all major carcinomas but not in healthy subjects or patients with nonmalignant diseases. Clin Cancer Res 10: 6897-6904, 2004.

36. Zhang L, Ridgway LD, Wetzel MD, Ngo J, Yin W, Kumar D, Goodman JC, Groves MD and Marchetti D: The Identification and characterization of breast cancer CTCs competent for brain metastasis. Sci Transl Med 5: 180ra48, 2013.

37. Yu M, Bardia A, Aceto N, Bersani F, Madden MW, Donaldson MC, Desai R, Zhu H, Comaills V, Zheng Z, et al: Cancer therapy. Ex vivo culture of circulating breast tumor cells for individualized testing of drug susceptibility. Science 345: 216-220, 2014

38. Bertotti A, Migliardi G, Galimi F, Sassi F, Torti D, Isella C, Corà D, Di Nicolantonio F, Buscarino M, Petti C, et al: A molecularly annotated platform of patient-derived xenografts ('xenopatients') identifies HER2 as an effective therapeutic target in cetuximab-resistant colorectal cancer. Cancer Discov 1: 508-523, 2011.

39. Hughes AD, Marshall JR, Keller E, Powderly JD, Greene BT and King MR: Differential drug responses of circulating tumor cells within patient blood. Cancer Lett 352: 28-35, 2014

40. Hodgkinson CL, Morrow CJ, Li Y, Metcalf RL, Rothwell DG, Trapani F, Polanski R, Burt DJ, Simpson KL, Morris K, et al: Tumorigenicity and genetic profiling of circulating tumorcells in small-cell lung cancer. Nat Med 20: 897-903, 2014.

41. Cancer Genome Atlas Network: Comprehensive molecular portraits of human breast tumours. Nature 490: 61-70, 2012.

42. Peters LJ: Radiation therapy tolerance limits. For one or for all?-Janeway Lecture. Cancer 77: 2379-2385, 1996.

43. van Dijk LK, Boerman OC, Kaanders JH and Bussink J: PET Imaging in head and neck cancer patients to monitor treatment response: A future role for EGFR-targeted imaging. Clin Cancer Res 21: 3602-3609, 2015.

44. Stebbing J, Paz K, Schwartz GK, Wexler LH, Maki R, Pollock RE, Morris R, Cohen R, Shankar A, Blackman G, et al Patient-derived xenografts for individualized care in advanced sarcoma. Cancer 120: 2006-2015, 2014.

45. Garralda E, Paz K, López-Casas PP, Jones S, Katz A, Kann LM, López-Rios F, Sarno F, Al-Shahrour F, Vasquez D, et al: Integrated next-generation sequencing and avatar mouse models for personalized cancer treatment. Clin Cancer Res 20: 2476-2484, 2014.
46. Jones N, Bonnet F, Sfar S, Lafitte M, Lafon D, Sierankowski G, Brouste V, Banneau G, Tunon de Lara C, Debled M, et al: Comprehensive analysis of PTEN status in breast carcinomas. Int J Cancer 133: 323-334, 2013.

47. Berg JS, Amendola LM, Eng C, Van Allen E, Gray SW, Wagle N, Rehm HL, DeChene ET, Dulik MC, Hisama FM, et al: Processes and preliminary outputs for identification of actionable genes as incidental findings in genomic sequence data in the Clinical Sequencing Exploratory Research Consortium. Genet Med 15: 860-867, 2013

48. Garraway LA and Jänne PA: Circumventing cancer drug resistance in the era of personalized medicine. Cancer Discov 2: 214-226, 2012.

49. Chiron M, Bagley RG, Pollard J, Mankoo PK, Henry C, Vincent L, Geslin C, Baltes N and Bergstrom DA: Differential antitumor activity of aflibercept and bevacizumab in patient-derived xenograft models of colorectal cancer. Mol Cancer Ther 13: 1636-1644, 2014

50. Monsma DJ, Cherba DM, Eugster EE, Dylewski DL, Davidson PT, Peterson CA, Borgman AS, Winn ME, Dykema KJ, Webb CP, et al: Melanoma patient derived xenografts acquire distinct Vemurafenib resistance mechanisms. Am J Cancer Res 5: 1507-1518, 2015.

51. Clohessy JG and Pandolfi PP: Mouse hospital and co-clinical trial project-from bench to bedside. Nat Rev Clin Oncol 12: 491-498, 2015.

52. Lunardi A and Pandolfi PP: A co-clinical platform to accelerate cancer treatment optimization. Trends Mol Med 21: 1-5, 2015.

53. Chen Z, Akbay E, Mikse O, Tupper T, Cheng K, Wang Y, Tan X, Altabef A, Woo SA, Chen L, et al: Co-clinical trials demonstrate superiority of crizotinib to chemotherapy in ALK-rearranged non-small cell lungcancer and predict strategies to overcome resistance. Clin Cancer Res 20: 1204-1211, 2014.

54. Kwong LN, Boland GM, Frederick DT, Helms TL, Akid AT, Miller JP, Jiang S, Cooper ZA, Song X, Seth S, et al: Co-clinical assessment identifies patterns of BRAF inhibitor resistance in melanoma. J Clin Invest 125: 1459-1470, 2015.

55. Malaney P, Nicosia SV and Davé V: One mouse, one patient paradigm: New avatars of personalized cancer therapy. Cancer Lett 344: 1-12, 2014

56. Nardella C, Lunardi A, Patnaik A, Cantley LC and Pandolfi PP The APL paradigm and the 'co-clinical trial' project. Cancer Discov 1: 108-116, 2011

57. Chen Z, Cheng K, Walton Z, Wang Y, Ebi H, Shimamura T, Liu Y, Tupper T, Ouyang J, Li J, et al: A murine lung cancer co-clinical trial identifies genetic modifiers of therapeutic response. Nature 483: 613-617, 2012.

58. Cassidy JW, Caldas C and Bruna A: Maintaining tumor heterogeneity in patient-derived tumor xenografts. Cancer Res 75: 2963-2968, 2015

59. Morton JJ, Bird G, Keysar SB, Astling DP, Lyons TR, Anderson RT, Glogowska MJ, Estes P, Eagles JR, Le PN, et al: XactMice: Humanizing mouse bone marrow enables microenvironment reconstitution in a patient-derived xenograft model of head and neck cancer. Oncogene 35: 290-300, 2016.

60. Julien S, Merino-Trigo A, Lacroix L, Pocard M, Goéré D, Mariani P, Landron S, Bigot L, Nemati F, Dartigues P, et al: Characterization of a large panel of patient-derived tumor xenografts representing the clinical heterogeneity of human colorectal cancer. Clin Cancer Res 18: 5314-5328, 2012.

61. Hidalgo M, Amant F, Biankin AV, Budinská E, Byrne AT, Caldas C, Clarke RB, de Jong S, Jonkers J, Mælandsmo GM, et al: Patient-derived xenograft models: An emerging platform for translational cancer research. Cancer Discov 4: 998-1013, 2014.

62. Cottu P, Marangoni E, Assayag F, de Cremoux P, Vincent-Salomon A, Guyader Ch, de Plater L, Elbaz C, Karboul N, Fontaine JJ, et al: Modeling of response to endocrine therapy in a panel of human luminal breast cancer xenografts. Breast Cancer Res Treat 133: 595-606, 2012.

63. DeRose YS, Wang G, Lin YC, Bernard PS, Buys SS, Ebbert MT, Factor R, Matsen C, Milash BA, Nelson E, et al: Tumor grafts derived from women with breast cancer authentically reflect tumor pathology, growth, metastasis and disease outcomes. Nat Med 17: 1514-1520, 2011.

64. Zhang X, Claerhout S, Prat A, Dobrolecki LE, Petrovic I, Lai Q, Landis MD, Wiechmann L, Schiff R, Giuliano M, et al: A renewable tissue resource of phenotypically stable, biologically and ethnically diverse, patient-derived human breast cancer xenograft models. Cancer Res 73: 4885-4897, 2013. 
65. Kabos P, Finlay-Schultz J, Li C, Kline E, Finlayson C, Wisell J, Manuel CA, Edgerton SM, Harrell JC, Elias A and Sartorius CA: Patient-derived luminal breast cancer xenografts retain hormone receptor heterogeneity and help define unique estrogen-dependent gene signatures. Breast Cancer Res Treat 135: 415-432, 2012.

66. Petrillo LA, Wolf DM, Kapoun AM, Wang NJ, Barczak A Xiao Y, Korkaya H, Baehner F, Lewicki J, Wicha M, et al: Xenografts faithfully recapitulate breast cancer-specific gene expression patterns of parent primary breast tumors. Breast Cancer Res Treat 135: 913-922, 2012.

67. Moro M, Bertolini G, Tortoreto M, Pastorino U, Sozzi G and Roz L: Patient-derived xenografts of non small cell lung cancer: Resurgence of an old model for investigation of modern concepts of tailored therapy and cancer stem cells. J Biomed Biotechnol 2012: 568567, 2012.

68. Nakajima T, Geddie W, Anayama T, Ko HM, da Cunha Santos G, Boerner S, Wang T, Wang YH, Li M, Pham NA, et al: Patient-derived tumor xenograft models established from samples obtained by endobronchial ultrasound-guided transbronchial needle aspiration. Lung Cancer 89: 110-114, 2015.

69. Dangles-Marie V, Pocard M, Richon S, Weiswald LB, Assayag F, Saulnier P, Judde JG, Janneau JL, Auger N, Validire P, et al: Establishment of human colon cancer cell lines from fresh tumors versus xenografts: Comparison of success rate and cell line features. Cancer Res 67: 398-407, 2007.

70. Puig I, Chicote I, Tenbaum SP, Arqués O, Herance JR, Gispert JD, Jimenez J, Landolfi S, Caci K, Allende H, et al: A personalized preclinical model to evaluate the metastatic potential of patient-derived colon cancer initiating cells. Clin Cancer Res 19: 6787-6801, 2013.

71. Peng S, Creighton CJ, Zhang Y, Sen B, Mazumdar T, Myers JN, Lai SY, Woolfson A, Lorenzi MV, Bell D, et al: Tumor grafts derived from patients with head and neck squamous carcinoma authentically maintain the molecular and histologic characteristics of human cancers. J Transl Med 11: 198, 2013.

72. Priolo C, Agostini M, Vena N, Ligon AH, Fiorentino M, Shin E, Farsetti A, Pontecorvi A, Sicinska E and Loda M: Establishment and genomic characterization of mouse xenografts of human primary prostate tumors. Am J Pathol 176: 1901-1913, 2010.
73. Wetterauer C, Vlajnic T, Schüler J, Gsponer JR, Thalmann GN, Cecchini M, Schneider J, Zellweger T, Pueschel H, Bachmann A, et al: Early development of human lymphomas in a prostate cancer xenograft program using triple knock-out immunocompromised mice. Prostate 75: 585-592, 2015.

74. Boone JD, Dobbin ZC, Straughn JM Jr and Buchsbaum DJ: Ovarian and cervical cancer patient derived xenografts: The past, present, and future. Gynecol Oncol 138: 486-491, 2015.

75. Bankert RB, Balu-Iyer SV, Odunsi K, Shultz LD, Kelleher RJ Jr, Barnas JL, Simpson-Abelson M, Parsons R and Yokota SJ: Humanized mouse model of ovarian cancer recapitulates patient solid tumor progression, ascites formation, and metastasis. PLoS one 6: e24420, 2011

76. Han C, Shen J, Wang H, Yu L, Qian X, Liu B and Guan W: Personalized primary tumor xenograft model established for the pre-clinical trial to guide postoperative chemotherapy. Med Hypotheses 79: 705-708, 2012.

77. Xue A,Julovi SH,Samra JS, et al: Establishment of patient-derived subrenal capsule xenograft of pancreatic cancersin NOD/SCID mice: Potential models for drug responses of personalized chemotherapy. In: Proceedings of the Australian Health and Medical Research Congress (AHMRC), 2012.

78. Pavía-Jiménez A, Tcheuyap VT and Brugarolas J: Establishing a human renal cell carcinoma tumorgraft platform for preclinical drug testing. Nat Protoc 9: 1848-1859, 2014.

79. Mohseni MJ, Amanpour S, Muhammadnejad S, Sabetkish S, Muhammadnejad A, Heidari R, Haddadi M, Mazaheri Z, Vasei M and Kajbafzadeh AM: Establishment of a patient-derived Wilms tumor xenograft model: A promising tool for individualized cancer therapy. J Pediatr Urol 10: 123-129, 2014.

(c) (i) () $(9)$ This work is licensed under a Creative Commons

Attribution-NonCommercial-NoDerivatives 4.0 International (CC BY-NC-ND 4.0) License. 